\section{Conference Proceedings}

The proceedings of the Third Decennial International Conference on Nosocomial Infections, which was held this past summer in Atlanta, Georgia, is scheduled for publication as a supplement to the A merican Journal of $M$ edicine next month. A copy will be sent by the American Hospital Association to the chief executive officers of all US hospitals for distribution to the hospitals' infection control programs, so be on the lookout! In addition, the September issue of Infection Control and Hospital Epidemiology will have an article summarizing several of the National Nosocomial Infection Surveillance Study presentations that were made by Centers for Disease Control personnel at the conference.

\title{
Job Board-Centers for Disease Control
}

The Centers for Disease Control is seeking a person for its Bacterial Studies Section, Division of STD/HIV Prevention. The section conducts epidemiologic, clinical, and evaluation research, including studies of antibiotic resistance and autotype-serotype patterns of gonococcal isolates from 22 US cities and clinical trials of therapies and diagnostic tests for gonorrhea, chlamydia, syphilis, trichomonas, and chancroid. In addition, the section is conducting a multi-center study of epidemic increases in syphilis, cohort studies of chlamydia and bacterial vaginosis in pregnancy, and a cohort study of pelvic inflammatory disease.

Opportunities exist to investigate a variety of questions concerning the epidemiology, natural history, clinical management, and development of prevention programs for chlamydia, gonorrhea, syphilis, chancroid, and trichomoniasis, and to investigate disease syndromes associated with STD (e.g., salpingitis, infertility, bacterial vaginosis, and urethritis).

The candidate must be an MD with training and experience in epidemiology and infectious diseases and must possess the ability to conduct epidemiologic studies, clinical trials, and evaluation research.

For further information contact Dr. Robert Johnson, Dr. George Schmid, or Mr. Al Harry. Interested individuals should send a $\mathrm{CV}$ with the names and addresses of three references to Robert E. Johnson, MD, MPH, Division of STD/HIV Prevention (E02), Centers for Disease Control, Atlanta, GA 30333. Telephone (404) 6392580.

\section{Announcement: SHEA's Second Annual Scientific Meeting}

Baltimore-April-Hospital Epidemiology-The perfect trio!

Our second annual scientific meeting will be April 12-14, 1992, at the Omni Inner Harbor Hotel, Baltimore, Maryland. Reserve the date now.

The objectives of the conference are: to review methods for surveillance and prevention of adverse clinical outcomes; to update and review trends in nosocomial infections and pathogens, antimicrobial resistance, and human immunodeficiency virus (HIV) / acquired immunodeficiency syndrome (AIDS) prevention; to review progress in achieving National Year 2000 objectives for preventing nosocomial infection in intensive care units and in surgical patients; to present information on surveillance and prevention of occupational infections and injuries; and to identify areas for future research.

These broad objectives should interest a large target audience, including not only hospital epidemiologists and infection control practitioners, but also quality improvement professionals, hospital administrators, surgeons, intensivists, and microbiologists.

The conference format will include symposia, scientific sessions, poster sessions, and industry exhibits. Original scientific contributions will be solicited actively. Abstract forms, registration forms, and housing forms will be included in the preliminary program.

The chair and co-chair for this exciting event are Drs. C. Glen Mayhall and John P. Burke, respectively. For further information, please contact
SHEA, 875 Kings Highway, Suite 200, West Deptford, NJ 08096. Telephone (609) 845-1636.

\section{SHEA \\ Membership List Available}

A SHEA membership list is available for individuals or organizations who want to target mailings to hospital epidemiologists and other infectious disease specialists. The costs for a onetime mailing list are as follows: a commercial business, $\$ 500$; a not-for-profit organization, $\$ 150$; and a member using the list for research purposes, $\$ 50$. To order the list, contact SHEA, 875 Rings Highway, Suite 200, West Deptford, NJ 08096. Telephone (609) 8451636. 